\title{
Great expectations
}

\author{
The decision by the European Council to lower the expenditure ceiling for the next seven-year framework \\ programme comes during a time of great debate on the distribution of research funding. The selection of \\ two flagship projects that will each receive $€ 500$ million over the next decade raises further questions.
}

The European Union 'Flagships initiative' was launched in 2010 as a new challenging Future and Emerging Technologies (FET) scheme. Flagship projects are expected to offer a long-term, scientific vision that deserves coordinated financial and scientific support from the European Union and its member states for their success. Six pilot ideas ${ }^{1}$, encompassing topical areas from robot or electronic assistants to integrated platforms for medical or socio-economic and environmental data, were selected in 2011 and the teams behind them were given a year to showcase their potential for advancing scientific understanding, generating market interest and, more broadly, improving citizens standard of living.

In January 2013, two of the pilot ideas the Human Brain Project (HBP) and Graphene - were awarded $€ 1$ billion each in funding, half of which will be directly supplied by the European Union. It is likely they will remain under scrutiny from the scientific community and, following the recent cuts to the European Union budget, from the wider public for years to come.

The goal of the HBP is to unite the fragmented landscape of studies into the workings of the human brain to develop the most detailed computational model of how it works. The project is expected to provide new computing paradigms with an unprecedented degree of sophistication and, ultimately, to spur the development of new therapies for brain diseases ${ }^{2}$. In a different scientific arena, the Graphene flagship aims to bring graphene and correlated two-dimensional materials from the confines of academic research to the core of a new generation of information and communication technology ${ }^{3}$.

The remarkable rise of the interest in graphene over the past decade, spurred by its exceptional electronic, optical, mechanical and thermal properties, is well $\mathrm{known}^{4}$. Europe has played a central role in establishing these fundamental properties and making clear their potential for possible technological applications. However, as other commentators have noted ${ }^{5}$, the subsequent explosion of published articles and patents, as well as the first steps to commercialize the use of graphene in practical applications, has mainly taken place in the USA and Asia. In

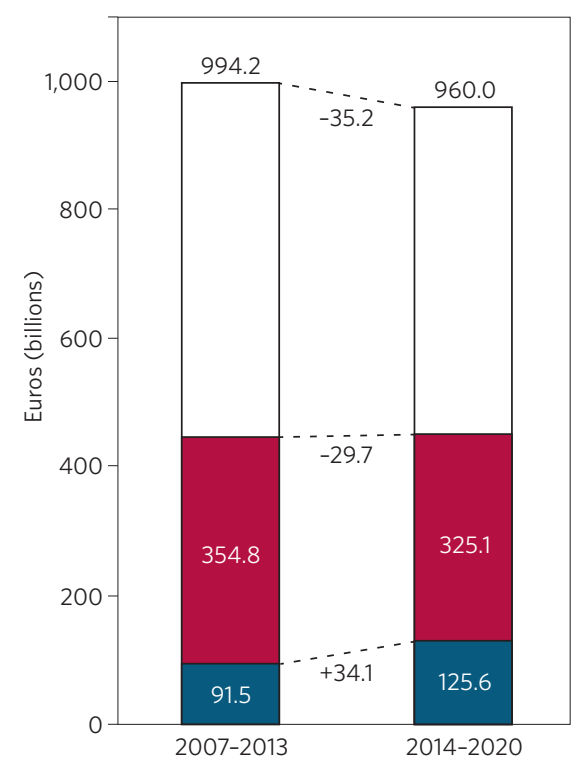

Figure 1 | Summary of the proposed multi-annual financial framework (MFF) and comparison with present appropriations. The total commitment appropriations (€994.2 billion for 2007-2013, and $€ 960.0$ billion for 2014-2020) include the budgets for competitiveness for growth and jobs (blue), economic, social and territorial cohesion (red) and other initiatives (white). Variations of budget commitments are given in the middle. Data taken from ref. 6.

this respect, the risk carried by this flagship project is twofold. First, formidable technical challenges must be overcome for graphene to form the basis of so-called disruptive technologies: above all, the notorious absence of a non-zero bandgap and the high costs associated with producing large-area and defect-free sheets of the material. Second, filling the large gap between fundamental research and industrial development is no easy task, and Europe and its industrial players have some catching up to do if they are to reach the forefront of this field. To achieve the stated aim of 'manifold return on the investments' for the European Union, both challenges must be met.

Investment in the Graphene project and, more generally, in these FET flagships seems even larger once their cost is placed within the wider context of the latest cuts to the European Union budget announced in February 2013. Following sustained pressure by researchers from the whole continent, the European Council has outlined a new multi-annual financial framework (MFF) that protects funds for research, innovation and education from the current financial crisis ${ }^{6}$. The structure of the proposed MMF and a comparison with the corresponding current appropriations are summarized in Fig. 1. The budget for competitiveness is in line for an increase of $€ 34.1$ billion (Fig. 1; blue). However, the research framework programme Horizon 2020, which is included into this section of the financial statement, will be some way below the $€ 80$ billion previously put forward by the European Commission ${ }^{7}$. This will require a tough reorganization in the distribution of funding, while preserving the $€ 1$ billion award advertised for Graphene and HBP (ref. 8). Moreover, looking at the MFF more broadly, larger cuts will involve the economic and social cohesion (Fig. 1; red), and limited subsidies will be allocated to youth unemployment. In a period of sustained economic uncertainty, this deal proposed by the European Council clearly underlines the hopes it is pinning on research to ensure long-term growth.

Graphene and HBP will share the biggest piece of a cake that has been defended tooth and nail by the entire scientific community. At the same time, other challenging research fields will face a belt-tightening policy that is going to create some degree of disappointment, with the broader cuts in the next MFF offering little comfort. So it is no surprise that these two ambitious flagship projects are burdened with great responsibility. Of course, fundamental science cannot be blamed for not achieving all its stated goals, and research has a knack of generating the unexpected. But the premises for a decade of meticulous attention to the progress of the flagship projects are all in place.

\footnotetext{
References

1. http://go.nature.com/HJJSOA

2. http://www.humanbrainproject.eu/files/HBP_flagship.pdf

3. Novoselov, K. S. et al. Nature 490, 192-200 (2012)

4. Geim, A. K. \& Novoselov, K. S. Nature Mater. 6, 183-191 (2007),

5. Tannock, Q. Nature Mater. 11, 2-5 (2012)

6. http://go.nature.com/QF1ZVs

7. Nature Mater. 11, 477 (2012).

8. http://go.nature.com/nAArep
} 